\title{
Congenital erosive and vesicular dermatosis
}

INSERM

\section{Source}

INSERM. (1999). Orphanet: an online rare disease and orphan drug data base. Congenital erosive and vesicular dermatosis. ORPHA:231573

Congenital erosive and vesicular dermatosis is a rare, idiopathic skin disease characterized by widespread, congenital, superficial erosions and vesicles (often involving more than $75 \%$ of the body) which heal leaving scars with a supple, symmetrical, reticulated pattern, frequently resulting in cicatricial alopecia and hyperthermia and/or hypohydrosis. Nail anomalies, neurodevelopmental and ophtalmologic abnormalities, tongue atrophy and preterm birth, with or without history of choriomnionitis, are commonly associated. 